\title{
Time series analysis of China's service trade based on ARIMA model
}

\author{
Wang Pengliang \\ South China University of Technology, Panyu District, Guangzhou, Guangdong \\ ifengse@foxmail.com
}

\begin{abstract}
Since the international trade and global development environment tend to be severe, all of the countries are looking for new economic growth points. Therefore, service trade is widely concerned. Now the opportunities and challenges of trade in services coexist. To study the development of China's service trade, the ARIMA model was used to analyze the time series data of China's service trade volume from 1982 to 2015. R was used to build the model. From the model checking, ARIMA $(2,3,2)$ was selected. With the predict of $\operatorname{ARIMA}(2,3,2)$, the projected value for 2016 is $\$ 749.9989$ billion, so that China's trade in services will be stable development. Some policy recommendations were also made to improve China's service trade.
\end{abstract}

Keywords: service trade; ARIMA model; trade forecast

\section{Introduction}

In the background of global economic globalization, economic integration and the upgrading of global industrial structure, the development of global service trade is very rapid. In order to keep up with the pace of world trade in services, China is constantly developing service trade. We need to pay attention to the problems in service trade, and improve our export status to promote the development of China's service trade.

\section{Analysis of import and export of service trade in China}

\subsection{Present situation of import and export of service trade in China}

Since China joined the WTO in 2001, Service trade has a rapid development, As shown in Figure 1 and Figure 2.In addition to the financial crisis in 2009, service trade import and export volume has declined, other years have maintained good development. 2015, China's total services trade is about $\$ 713$ billion, an increase of $14.6 \%$ over 2014 , the growth rate is much higher than the average level of global trade in services.

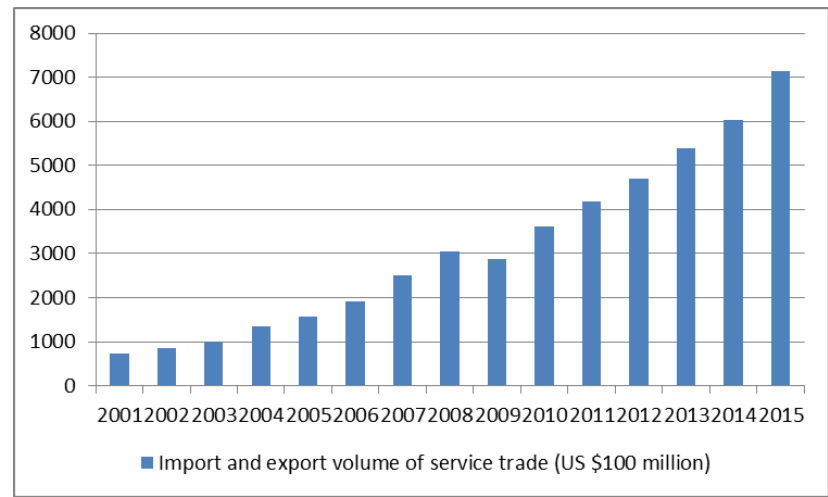

Figure 1. China's volume of service trade ${ }^{1}$

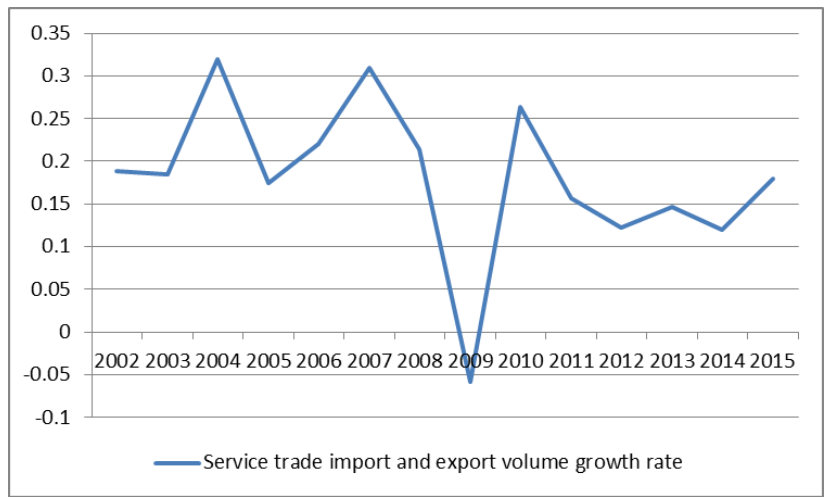

Figure 2. China's service trade growth rate ${ }^{2}$

\footnotetext{
1 * data sources: 2015 China Statistical Yearbook and the Ministry of Commerce, Department of Trade in Services

2 * data sources: calculated according to the 2015 China Statistical Yearbook and the Ministry of Commerce, Department of Trade in Services.
} 


\subsection{Problems in the development of China's service trade import and export}

There are still many problems in the development of China's service industry. There is still a big gap between China's service industry and developed countries, the proportion of service trade in China's total economy is relatively low, the structure of service trade needs to be optimized.

In the situation of sustained trade surplus, the trade in services has a large deficit, and the deficit is still showing a trend of expanding. In 2015, China's trade deficit of 136.62 billion US dollars, the overall trade deficit is still large. The tourism trade deficit of 123.74 billion US dollars, an increase of $14.7 \%$, is the biggest source of trade deficit. Followed by the transport services, exclusive royalties and royalties, the balance of the two were 48.8 billion US dollars, 20.91 billion US dollars, a slight decline compared to 2014. The decline in the competitiveness index of trade shows that the competitiveness of trade in services continues to decline. In recent years, although the international competitiveness of eight service trade projects such as finance, construction, computer and information service and consulting has been enhanced. This is directly related to the improvement of China's human resources and the development of service outsourcing. However, the international competitiveness of the five service trade projects, such as advertising and publicity, transportation, tourism, film and audio-visual services, has weakened.

\subsection{Prospect of China's Service Trade Development}

\subsubsection{The international environment has steadily increased}

The current world economic slow growth, international trade development environment is still unstable, to a certain extent, dragged down the development of trade in services. But the global financial market transactions active, some areas of service trade development prospects are optimistic.

Global demand for services is generally weak. Emerging economies and developing countries overall economic growth continued to fall, rapid growth in the service market situation has slowed, but overall still on the rise.

\subsubsection{The domestic environment is constantly optimized}

China's economic development has entered a new normal, the status and role of the service industry in economic growth has improved significantly, the policy system supporting the development of trade in services has been improved, and the function of service trade promotion platform has been enhanced.

The steady development of the service industry lays a solid foundation for trade in services. With the accelerated pace of economic restructuring, the service industry in China's economy is more and more important. Service industry itself is also a rapid transformation and upgrading, and showing a smart, professional trend, the new service industry is facing a rare historical opportunity for development.

The policy system to support the development of trade in services has been gradually improved. In recent years, the Chinese government has been actively expanding the opening of service industries and supporting the policy measures on trade in services, which has played a strong role in promoting the development of trade in services.

\section{Analysis of Service Trade Based on ARIMA Model}

\section{1 the building process of ARIMA model}

The ARIMA model is based on the stationary time series. Therefore, when modeling a discrete time series, we should first study the stationarity of the time series, and then analyze and judge the data sequence generation process.

The ARIMA model includes moving average process (MA), autoregressive process (AR), 
autoregressive moving average process (ARMA), and ARIMA process according to whether the original sequence is stationary or not.

Autoregressive moving average (ARMA) model: $\operatorname{ARMA}(p, q)$ is a hybrid process of autoregressive moving averages. The formula is:

$$
y_{t}=\varphi_{1} y_{t-1}+\varphi_{2} y_{t-2}+\cdots+\varphi_{p} y_{t-\mathrm{p}}+a_{t}-\theta_{1} a_{t-1}-\theta_{2} a_{t-2}-\cdots-\theta_{q} a_{t-\mathrm{q}}
$$

The ARIMA model is the arithmetic sum of autoregressive AR model and moving average MA model, where I is the inverse of the difference. Where $\left\{a_{t}\right\}$ is a white noise sequence that satisfies the mean and constant variance of 0 and $\varphi_{i}$ is the estimated parameter of the model, $\theta_{i}$ is the estimated parameter of the model.

\subsection{Constructing ARIMA Model of Service Trade}

\subsubsection{Data selection}

The data of this paper are derived from the China Statistical Yearbook 2015 and the Ministry of Commerce, Department of Trade in Services. The selected year is from 1982 to 2015, of which, 1982-2014 data are used as modeling samples and 2015 trade data as posterior sample to judge the validity of the model estimation. In this paper, we use R 3.3.2 to analyze, model, test and predict the results.

\subsubsection{Model Construction}

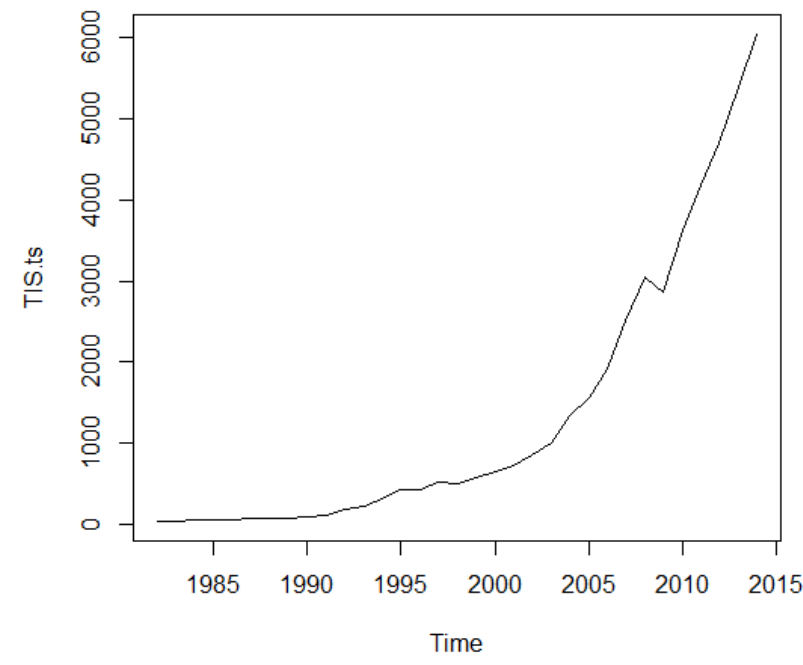

Figure 3. Time - series chart of trade in services

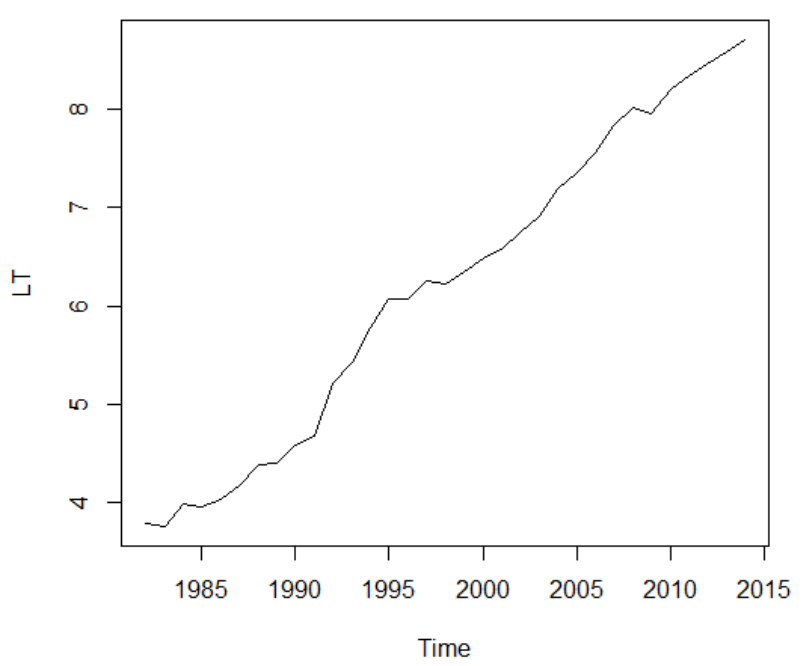

Figure 4. Logarithmic time series chart Figure 3 shows the time series of China's trade in services. As can be seen, the total value of imports and exports of China's trade in services has increased exponentially. Therefore, the logarithm of the data is logically processed. The results are shown in Figure 4. The result is transformed into LT, we can see that the growth of trade volume LT has been transformed into a linear growth trend. In order to ensure the smoothness of the sequence, we need to carry out the unit root ADF test, according to ADF test, LT is a non-stationary sequence, there is a unit root. Therefore, we need to do differential operation on LT, and carry out ADF test one by one. From the software operation results, the first order difference and the second order difference of time series are nonstationary, the unit root of third order difference does not exist, the time series is stationary series, The third-order difference is denoted LTdiff. Therefore, $\mathrm{d}$ is 3 in the ARIMA model.

Next, we need to do LTFiff ACF and PCF map. The maximum hysteresis order is 20. It can be seen from the ACF diagram that the autocorrelation of the first order and the autocorrelation of the second order exceed the significant boundary, while the other autocorrelation values do not exceed the significant boundary, so we can determine the ARIMA model $\mathrm{p}$ is 2 . According to the PACF, it 
can be seen that the first-order and second-order partial autocorrelation values exceed the significant boundary, while the other partial autocorrelation values do not exceed the significant boundary. Therefore, $\mathrm{q}$ is 2 in the ARIMA model. Therefore, the ARIMA model we obtained is ARIMA $(2,3,2)$. According to the time series, we can get the results in Figure 5.

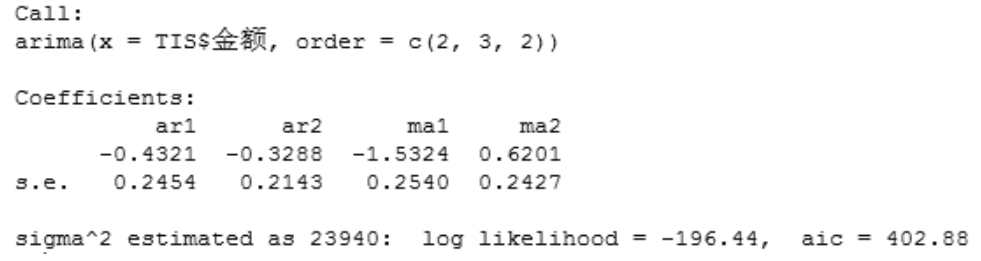

Figure 5. ARIMA $(2,3,2)$

From Figure 5 we can see that the results of the model ARIMA $(2,3,2)$, we can get the time series equation about LTdiff.

\subsubsection{Model checking}

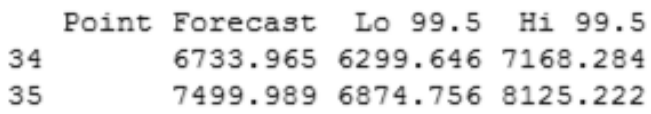

Figure 6. ARIMA $(2,3,2)$ prediction results

Forecasts from ARIMA(2,3,2)

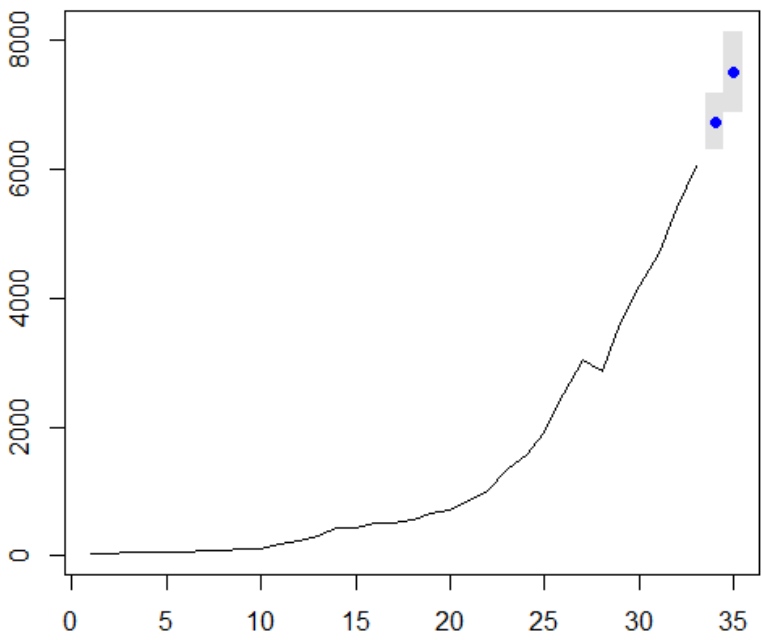

Figure 7 Model prediction
Series LTarimaforecast\$residuals

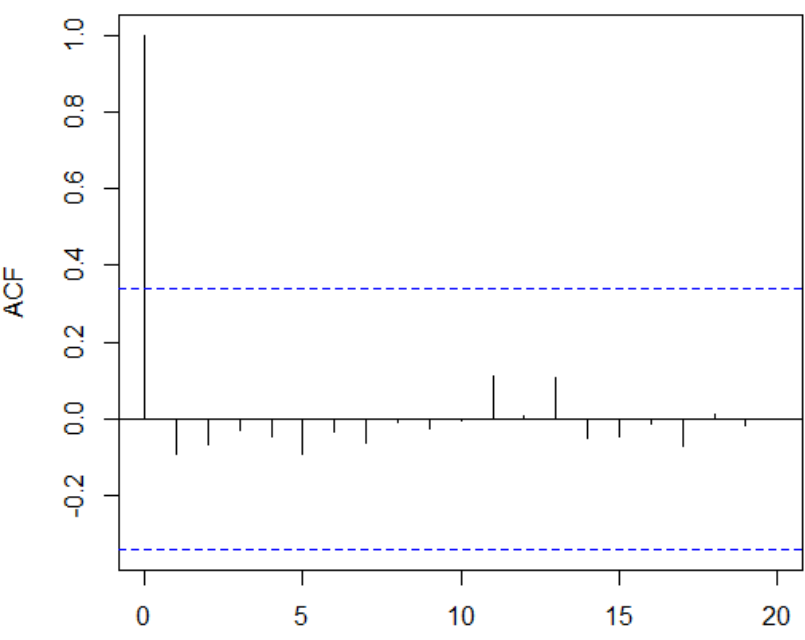

Figure 8 Residual correlation diagram

According to the forecast of Figure 7, we can see, The forecast for 2015 will be in a very high position, and the increase will be very large, we can find that the data predicted value of 673.3965 billion US dollars, while the value of trade in services in 2015 the actual value of 713 billion US dollars, Close to the upper limit of the predicted value.

From Figure 8, the ACF plot of the residuals shows that the sample autocorrelation values in the lag 1-20 order do not exceed the significant boundaries. According to the results of the Box-Ljung test in Figure 9, the $\mathrm{P}$ value is 1 , so we can conclude that there is no clear evidence that the prediction error is non-zero autocorrelation in the lag 1-20 order.

$$
\text { Box-Ljung test }
$$

data: LTarimaforecast\$residuals

$\mathrm{x}$-squared $=3.33$, df $=20, \mathrm{p}$-value $=1$

Figure 9 Box-Ljung test

\subsubsection{Model prediction}

The ARIMA model is used to forecast the import and export of service trade in 2016, The projected 
value for 2016 is $\$ 749.9989$ billion, Overall in line with expectations, China's trade in services will be stable development.

\section{Policy recommendations}

\subsection{Optimize the industrial structure of trade in services}

China must accelerate the development of the service industry and make full use of its advantages. And actively undertake the international transfer of services, integration into the global service trade in the industrial chain. Optimize the internal structure of the service industry, so that the development of the service industry is based on improving the labor force. At the same time, it encourages the development of service trade in the central region and the western region, introduces more capital to the service industry in inland areas, and adjusts the policies restricting the development of trade in services.

\subsection{Improve the management system and improve the laws and regulations}

The government should give full play to its role in macro-control to promote the development of China's trade in services, develop and improve the overall planning of trade in services and development strategies. In terms of laws and regulations, the government should constantly improve the laws and regulations in the field of service trade, establish the service trade laws, regulations and rules at different levels and at different stages, and in the legislative process, combine the actual situation of the development of service trade, Legal clarity, with practical maneuverability.

\subsection{Increase human capital investment and cultivate specialized talents}

In view of the shortage of professional talents in China's service trade, our government needs to take corresponding measures to train more high-level knowledge-based and applied talents. In some universities and research institutes to open more professional courses related to trade in services, increase investment in a variety of vocational skills training. The establishment of a sound service trade talent management library and service agencies, thereby enhancing the professional quality of employees and the quality of character.

\section{References}

[1] Chen Hong, Zhang Guangrong. An Empirical Study on the International Competitiveness of China 's Service Trade [J]. Management World, 2010, (10): 13-23.

[2] Cheng Zhifang, Lu Min. ARIMA Model and Forecast of the Scale of China's Service Trade [J] Foreign Economic Relations \& Trade, 2010 (12): 25-27.

[3] Tang Zhiming. Effects of Human Capital on China Service Trade International Competitiveness [J]. Reformation \& Strategy, 2016.

[4] Information on http://tradeinservices.mofcom.gov.cn/index.shtml

[5] Wan Hongxian. An Empirical Analysis on the Transformation of China 's Service Trade Growth Mode [J] World Economic Research, 2012, (11).

[6] Ramos P, Santos N, Rui R. Performance of state space and ARIMA models for consumer retail sales forecasting[J]. Robotics and Computer-Integrated Manufacturing, 2015, 34:151-163.

[7] Farooqi A. ARIMA model building and forecasting on imports and exports of Pakistan[J]. Pakistan Journal of Statistics \& Operation Research, 2014, 10(2):157.

[8] Liu X F. The Wavelet Analysis plus ARIMA model 2014 2017 Oil Import and Export Prediction[J]. Theory \& Practice of Finance \& Economics, 2014.

[9] Zhou A R, University F N. Comparative Study on the GDP Prediction of Fujian and Taiwan Based on ARIMA Model[J]. Taiwan Agricultural Research, 2015. 